\title{
Study of membrane attachment and in vivo co-localization of TerB protein from uropathogenic Escherichia coli KL53
}

\author{
Olga Alekhina, Lenka Valkovicova and Jan Turna \\ Department of Molecular Biology, Faculty of Natural Sciences, Comenius University, Bratislava, Slovakia
}

\begin{abstract}
The tellurite resistance operon has been found in a wide range of bacteria. We have previously identified the ter operon (terXYW and terZABCDEF) of the uropathogenic strain Escherichia coli KL53. In this study, we use an innovative approach to identify putative protein-protein interaction partners for one of the essential tellurite resistance proteins - TerB. We observe that $\mathrm{N}$-terminus of TerB attaches to the periplasmic membrane, while the C-terminus is partly localized in the cytoplasm. Subsequently, by methods of in vivo cross-linking and mass-spectroscopic analysis, we have determined the proteins from both the membrane and cytoplasmic fractions, which can potentially interact with TerB.
\end{abstract}

Key words: Tellurite resistance - Amphitropic protein - Cross-linking - TerB protein

\section{Introduction}

The soluble tellurium oxyanions are rare in nature. In general, tellurites $\left(\mathrm{TeO}^{-2}\right)$ and tellurates $\left(\mathrm{TeO}_{4}{ }^{-2}\right)$ are both toxic to prokaryotes and eukaryotes at very low concentrations (Taylor 1999). Several Gram-negative bacteria are particularly sensitive to tellurium salts, whereas some Gram-positive species exhibit natural resistance to these compounds (Taylor 1999; Chasteen et al. 2009). The experimental evidence accumulated during the last few years suggests, that tellurite exerts its toxicity, at least in part, through the generation of reactive oxygen species (ROS) (Borsetti et al. 2005; Calderon et al. 2006; Tremaroli et al. 2006; Perez et al. 2007; Zannoni et al. 2008). Notwithstanding this progress, the function of particular proteins in the ter gene cluster and the unifying mechanism of tellurite resistance $\left(\mathrm{Te}^{\mathrm{R}}\right)$ response cannot be proposed.

The genetic bases of $\mathrm{Te}^{\mathrm{R}}$ determinants have been investigated in numerous microorganisms (Jobling and Ritchie 1988; Turner et al. 1992, 1994; Whelan et al. 1997; Taylor 1999; Tantalean et al. 2003). The tellurite resistance encoded by the ter genes has been detected on the larger conjugative plasmid of Serratia marcescens (Whelan et al.

Correspondence to: Jan Turna, Department of Molecular Biology, Faculty of Natural Sciences, Comenius University, Mlynska dolina B2, 84215 Bratislava, Slovakia

E-mail: turna@fns.uniba.sk
1997), Alcaligenes sp. (Jobling and Ritchie 1988), Klebsiella pneumoniae (Chen et al. 2004) and also incorporated into the chromosome of Proteus mirabilis (Toptchieva et al. 2003) and Escherichia coli O157:H7 (Perna et al. 1998).

Chiang and co-workers (2008) have determined the 3D NMR solution structure of a tellurite resistance protein (TerB) from Klebsiella pneumoniae. The KP-TerB protein consists of seven $\alpha$-helices and a short $3_{10}$ helix after helix III. The unique property of the KP-TerB structure is that the positively and negatively charged clusters are formed by the $\mathrm{N}$-terminal positively and C-terminal negatively charged residues, respectively (Chiang et al. 2008).

The tellurite-resistant uropathogenic E. coli KL53 was found by testing of a group of clinical isolates for antibiotic and heavy metal ion resistance (Burian et al. 1988). ter operon of this strain takes place on the large conjugative plasmid pTE53 (Burian et al. 1998; Vavrova et al. 2006). The in vitro clone of pTE53 named pLK18 [GenBank Acc. N. AJ238043.1] contains the minimal part of the operon (terBCDEF) (Burian et al. 1998). Transposition mutagenesis approach by $\operatorname{Tn} 1737 \mathrm{Km}$-mediated gene disruption revealed that the genes ter $B$, ter $C$, ter $D$, ter $E$ are essential for tellurite resistance phenotype (Kormutakova et al. 2000).

The aim of present investigation was to determine the localization of TerB in the cell. By using in vivo protein cross-linking method with a chemical reagent DSP we have identified the partner proteins co-localizated with TerB. 


\section{Materials and Methods}

\section{Bacterial strains}

E. coli KL53 strain was obtained from the collection of the Department of Molecular Biology, Comenius University in Bratislava. Plasmid construction and all manipulations were carried out on the standard laboratory strain E. coli DH5a [ $F^{-}$endA1 glnV44 thi-1 recA1 relA1 gyrA96 deoR nupG Ф80dlacZ $\triangle M 15 \Delta\left(\right.$ lacZYA-argF)U169, hsdR17 $\left(r_{K}^{-} m_{K}{ }^{+}\right)$, $\lambda-]$. E. coli BL21(DE3) [ $F^{-}$ompT gal dcm lon hsd $S_{B}\left(r_{B}{ }^{-} m_{B}{ }^{-}\right)$ $\lambda$ (DE3 [lacI lacUV5-T7 gene 1 ind1 sam7 nin5])] was used for expression and overproduction of recombinant histidinetagged TerB protein.

\section{Construction of expression plasmids}

The coding region of ter $B$ gene was amplified by PCR from the total DNA of clinical isolate E. coli KL53. Oligonucleotide primers were based on the ter $B$ sequence (pETBforward 5'-CGGGATCCATGAGCTTTTTCGACAAAGTTAAAGGTGC-3' and pETBreverse 5'-CGGAATTCTCAGAGGCCAAATTCAGCGG-3'). The 453 bp PCR product was cloned into pGEM-T Easy Vector (Promega, Germany). For preparation of His-fusion protein, ter $B$ gene was re-cloned into the expression vector pET28a $(+)$ (Novagen, Germany) by digestion with BamHI and EcoRI restriction enzymes.

In order to determine which components (amino acids) of TerB are essential for membrane binding, we produced two truncated protein fragments (TerB 1-87 aa and TerB 88-151 aa). Asp88 was chosen as the cut point based on the reported 3D KP-TerB solution structure (Chiang et al. 2008) and the sequence alignment. These two protein fragments were obtained by cutting exactly between two domains, to avoid conformation changes. For this purpose TerB 1-87 and 88-151 aa fragments were amplified by using sense (terBN-forward 5'-GTCGCGGATCCATGAGCTTTTTCGACAAG-3'; terBC-forward 5'-GTCGCGGATCCATGGATGTTGAAATCGGCAA3', respectively) and antisense primers (terBN-reverse 5'-TCCGAATTCTCAGAAATCGAAGCTTGAAAC-3'; terBC-reverse 5'-TCCGAATTCTCAGAGGCCAAATTCAGCCG-3', respectively). The forward and reverse primers were designed with BamHI and EcoRI sites (underlined), respectively. PCR products were digested and cloned between the same sites of pET28a $(+)$ expression vector (Novagen, Germany).

\section{Protein expression}

The liquid culture of E. coli BL21(DE3) containing plasmid pET-terB were grown aerobically with vigorous shaking at $37^{\circ} \mathrm{C}$ in LB medium supplemented with $30 \mu \mathrm{g} \cdot \mathrm{ml}^{-1} \mathrm{kan}-$ amycin. The overnight culture was diluted $(1: 20)$ by fresh $\mathrm{LB}$ medium and grown at $37^{\circ} \mathrm{C}$ until the $\mathrm{OD}_{600}$ (the optical density at $600 \mathrm{~nm}$ ) reached $0.4-0.5$. Expression from the T7 RNA polymerase promoter was induced by addition of $1 \mathrm{mM}$ IPTG for $20 \mathrm{~min}$, this level of protein expression was chosen to adjust the amount of protein to its endogenous level to avoid artefacts.

\section{Purification of His-TerB by affinity chromatography}

Cells were harvested by centrifugation $(4000 \times g, 10 \mathrm{~min}$, $4^{\circ} \mathrm{C}$ ), washed with PBS, re-pelleted and resuspended in $2 \mathrm{ml}$ of PBS and then lysed by sonication. Debris and intact cells were removed by centrifugation $(15000 \times g$ for $20 \mathrm{~min})$. The supernatant (clarified cell lysate) was loaded onto M2 column (HIS-Select ${ }^{\circledR}$ Nickel Affinity gel column - SIGMA, Germany) prepared as recommended by the manufacturer. The column was gradually washed with Wash buffer $(50 \mathrm{mM}$ sodium phosphate, $0.3 \mathrm{M} \mathrm{NaCl}, 10 \mathrm{mM}$ imidazole). Bound His-tag protein was eluted with Elution buffer $(50 \mathrm{mM}$ sodium phosphate, $0.3 \mathrm{M} \mathrm{NaCl}, 250 \mathrm{mM}$ imidazole).

\section{Preparation of E. coli cellular fractions}

To find out the exact localization of TerB protein, we used an adequate in vivo method, i.e. separation of the cytoplasmic and membrane fractions of cells by ultracentrifugation (Huber et al. 2003) with additional sodium carbonate treatment. This step was crucial to prevent the micelle formation and to minimize the unwanted cytoplasmic contaminants which can be estimated as the membrane fraction proteins (Lopez-Villar et al. 2006). Cell lysate was prepared as described in previous paragraph. In addition, Protease Inhibitor Cocktail (SIGMA) was added prior sonication, and subsequently the sample was centrifuged (20 min, $15000 \times g, 4^{\circ} \mathrm{C}$ ) to remove inclusion bodies, cell debris and intact cells. After centrifugation $(115000 \times g$, $1 \mathrm{~h}, 4^{\circ} \mathrm{C}$ ), the pellet was resuspended in $100 \mathrm{mM} \mathrm{Na}_{2} \mathrm{CO}_{3}$ (pH 11) and stirred slowly on ice for $1 \mathrm{~h}$. The cytoplasmic fraction was obtained by ultracentrifugation $(115000 \times g$, $\left.1 \mathrm{~h}, 4^{\circ} \mathrm{C}\right)$, the pellet was resuspended and washed in $50 \mathrm{mM}$ PBS. Then, the membrane fraction was collected (115 000 $\left.\times g, 20 \mathrm{~min}, 4^{\circ} \mathrm{C}\right)$. Aliquots of total $(\mathrm{T})$ cell extract and equivalent amounts of cytoplasmic (C) and membrane (M) fractions were used for Western blot analysis.

\section{Co-localization study (in vivo cross-linking and mass-spec- troscopic analysis)}

E. coli BL21(DE3) cells containing expression plasmid pETterB were subjected to in vivo cross-linking experiment with the membrane permeable cross-linking reagent - DSP 
(dithiobis succinimidyl propionate; Pierce, USA). DSP was added to the induced cells at $2 \mathrm{mM}$ final concentration. After 2 hours on ice, the mixture was incubated at room temperature for $15 \mathrm{~min}$ to promote cross-linking. To stop the cross-linking reaction, $20 \mathrm{mM}$ Tris- $\mathrm{HCl}(\mathrm{pH} 7.5)$ was added. The DSP-treated cells were lysed by sonication. The cell lysate was used to prepare cytoplasmic and membrane fractions as described above. The products of cross-linking assay were separately purified by the affinity $\left(\mathrm{Ni}^{2+}\right)$ chromatography from both fractions. Polypeptides purified from the membrane and cytoplasmic fractions were analyzed by $12 \%$ SDS-PAGE with and without $\beta$-mercaptoethanol addition, because the disulphide bridges can be cleaved by reduction with mercaptans (Huber et al. 2003). Cross-linked protein products were digested by trypsin and analyzed by MALDITOF mass-spectroscopy to determine the nature of proteins cross-linked with His-TerB.

\section{Western blot}

Aliquots containing equal amounts of total proteins and proteins from cytoplasmic and membrane fractions were applied to $12 \%$ SDS-PAGE. Fractionated proteins were subsequently transferred to PVDF membranes (10 mA, 40 $\mathrm{min})$. TerB with His-tag was detected by the polyclonal rabbit anti-His antibodies at 1:10 000 dilution. We used the cytoplasmic marker namely $\beta$-galactosidase as a control which was detected by anti- $\beta$-galactosidase antibodies at the same dilution. The bands were visualized with ECL detection kit (Amersham, Germany) and X-ray film.

\section{UV difference spectroscopy}

UV spectroscopy was carried out on a Jasco V-570 spectrometer, with two quartz chambers cuvettes (Hellma, Germany), which were optically in tandem. Usage of the tandem cuvette allows accurate assessment of spectral differences between proteins in bound and free states by monitoring the difference between proteins that are free in separate chambers of the cuvette but optically mixed in tandem, and those that are physically mixed and bound, thereby maintaining identical optical activity, protein concentrations, and solvent conditions before and after binding (Kentsis et. al. 2002). Negative charged liposomes were used as artificial membrane (Sigma, Germany). TerB protein and liposomes were diluted in PBS, placed into separate chambers of the tandem cuvette. UV difference spectra $(200-330 \mathrm{~nm})$ were recorded at different incubation time points $(0,5,10$ and $30 \mathrm{~min})$ at room temperature (Creighton 1997). To qualify the obtained data of spectra TerB and liposomes in two chambers of the cuvette were mixed by inversion and allowed to equilibrate for $30 \mathrm{~min}$.

\section{Results}

In silico analysis of TerB

Previously, in silico analyses predicted the transmembrane localization of TerC protein. However, there is no available information regarding to the cellular localization of the other ter operon proteins. We were interested in TerB protein, because the NMR study had determined the TerB solution structure of Klebsiella pneumoniae (Chiang et al. 2008). We employed a sequence alignment of TerB homologues from enterobacteria. The data presented in Fig. 1A show high degree of conservation of these homologues.

A further analysis using surface electrostatic calculations (Fig. 2) revealed, that the substantial part of N-terminal of TerB has electropositive surface potential. These electropositive clusters can potentially interact with the cell membrane. According to our bioinformatic analysis, TerB protein is composed of $35 \%$ of positively charged residues, $60 \%$ of negatively charged ones, and only $5 \%$ are hydrophobic.

\section{Analysis of TerB localization by separation of the cytoplas- mic and membrane fractions}

By separation of cytoplasmic and membrane fractions it was clearly found that the full-length TerB was attached to the membrane and the same amount was detected in the cytoplasm (Fig. 1B). The N-terminal subdomain (1-87 aa residues) was found to be localized completely in the membrane fraction in contrast to C-terminal subdomain (88-151 aa residues) which appeared in both cytoplasmic and membrane fractions (Fig. 1C).

To prove that TerB is localized onto the membrane, we employed the UV difference spectroscopy method which revealed the conformational changes during interaction between the protein and an artificial membrane. According to our simulation data of electrostatic charge distribution on the protein surface, we decided to use negatively charged liposomes. Fig. 3 show that spectra have an increase in absorption at $235 \mathrm{~nm}$ at different incubation time.

\section{Co-localization of TerB with proteins}

The main purpose of co-localization study was to reveal potential protein-protein interaction candidates which cooperate with TerB in the cytoplasm and on the membrane. Within this frame, we chose in vivo protein cross-linking procedure with chemical reagent DSP. Proteins cross-linked to TerB were purified from the cytoplasmic and membrane fractions as shown in Fig. 4 . In the fractions the 8 candidates with high score above the threshold were detected. The most 


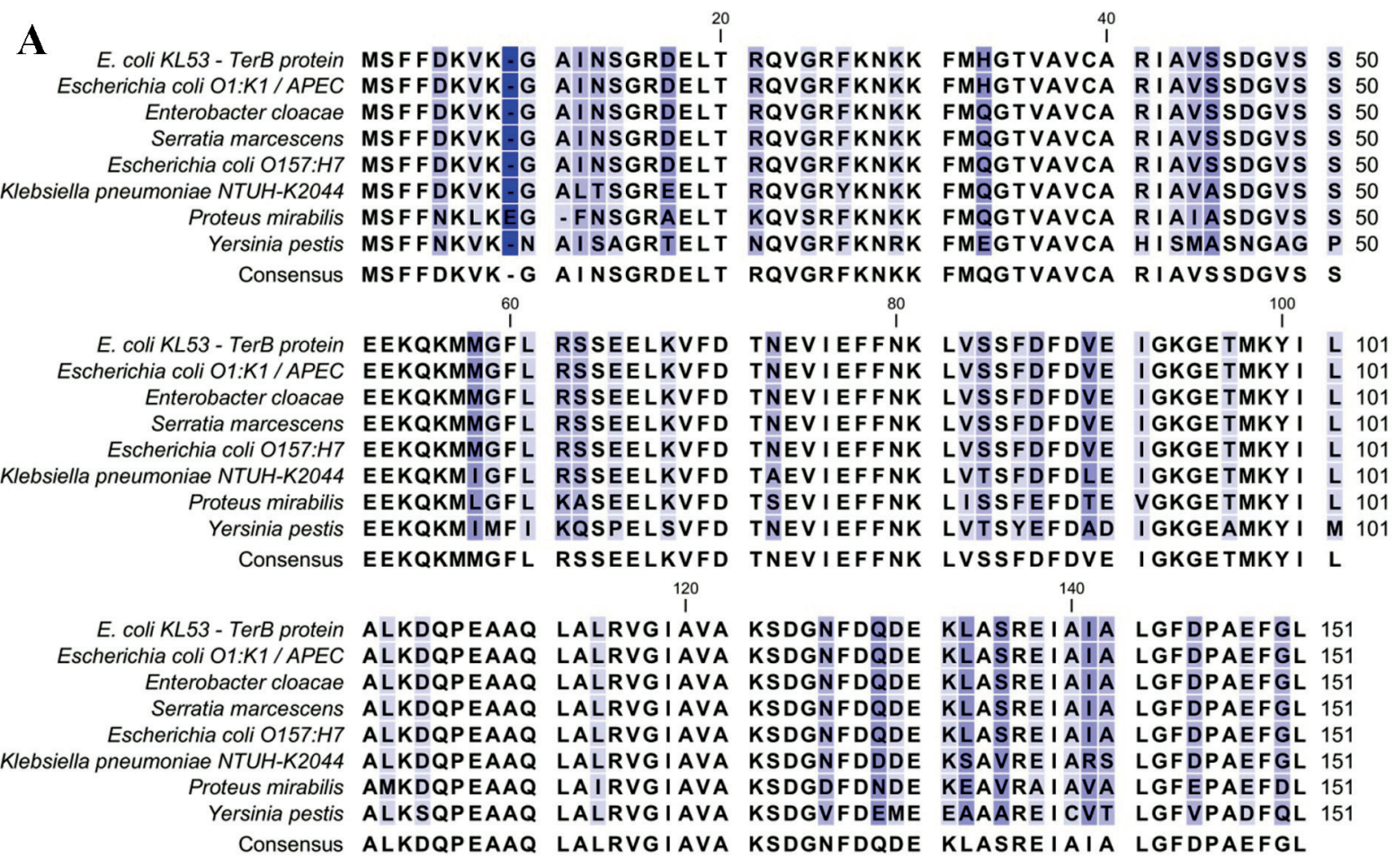

conservation

B

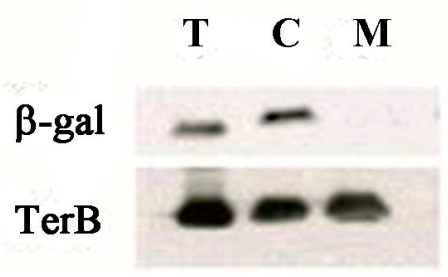

C $\quad \operatorname{TerB}_{1-87}$

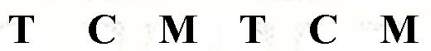

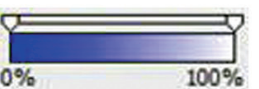

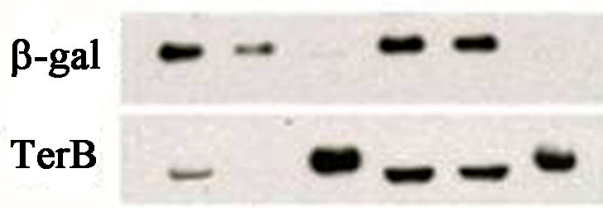

Figure 1. A. Sequence alignment of TerB homologues obtained from enterobacteria. The image was taken from JalView using the ClustalX scheme. B. Analysis of full length TerB localization by using preparation of cellular fractions with sodium carbonate treatment and Western blot detection. C. Mapping the region of TerB essential for membrane attachment. T, total lysate; C, cytoplasm fraction; M, membrane fraction. $\beta$-galactosidase used as a cytoplasmic marker.

intensive band (molecular weight $20.024 \mathrm{kDa}$ ) was identified as TerB, with a total score of 280 . Polypeptids determined as novel interaction partners of TerB, their MASCOT score, their function and some additional information are shown in Table 1.

\section{Discussion}

The tellurite resistance operon is composed of terXYW and terZABCDEF genes, but only four of the genes (terBCDE) have been documented to be essential for tellurite resistance maintenance (Burian et al. 1998; Kormutakova et al.
2000; Vavrova et al. 2006). We suppose that an investigation of ter operon at the protein level and also protein-protein interaction could be helpful for our understanding of the mechanism of tellurite resistance. Our results demonstrate that TerB is associated directly with the inner surface of membrane as well as being partly localized in the cytosol. The association of TerB protein with membrane might be regulated by its interaction with other proteins or by its covalent modification. Amphitropic proteins, that adhere directly to the biological membrane, attach to the bilayer by means of amphipathic helices, hydrophobic loops, ions, or covalently attached lipids (Johnson and Cornell 1999; Cornell and Taneva 2006). The UV spectra of TerB in 


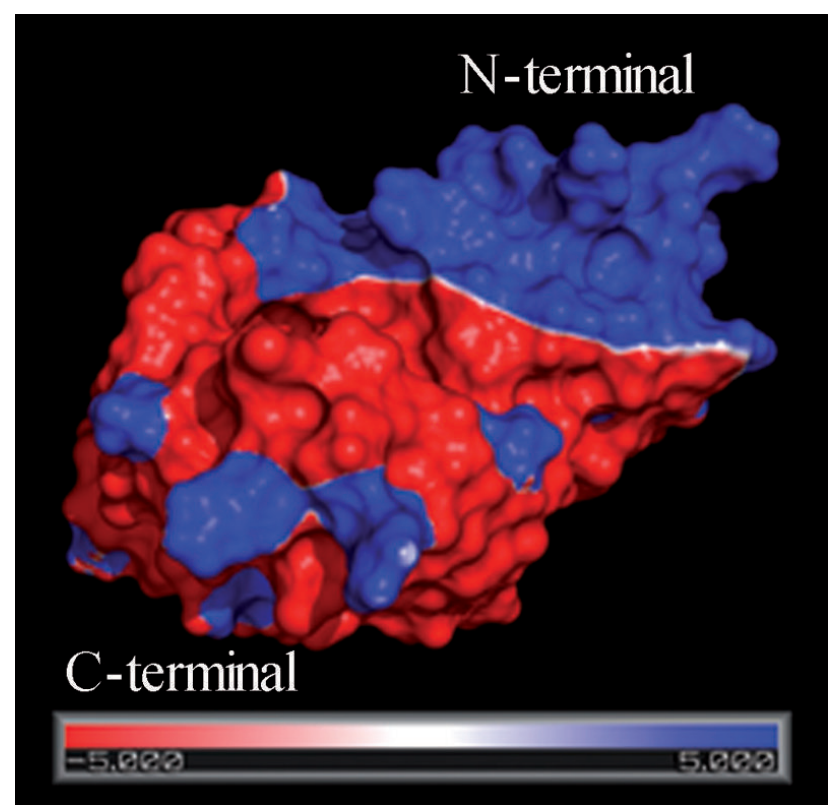

Figure 2. Stereoview of TerB protein in a GRASP representation showing the molecular surface coloured according to electrostatic potential (red, $-5 k T / e$; blue, $+5 k T / e$ ).

complex with an artificial membrane (Fig. 3) confirm our suggestions that TerB can be classified as a peripheral, amphitropic membrane protein.

In previous works, the structure of KP-TerB in Klebsiella pneumoniae was obtained using NMR (Chiang et al. 2008). According to our results of sequence alignment analysis we can conclude that TerB homologues are strongly conserved in different species (Fig. 1A). Another evidence of this strong conservation is the similarity of TerB structure at the secondary and tertiary structural levels.

The intermolecular forces that play a role in adhering of proteins to the lipid bilayer appear to be a combination of hydrophobic and electrostatic forces, or in some cases they are mainly electrostatic (Dym et al. 2000). Computer simulations using the GRASP program show an extensive area of positive electrostatic charge surrounding the N-terminal part of TerB protein (Fig. 2). Mapping the region proposed to be responsible for TerB attaching to the membrane help us to suggest that the N-part can facilitate the interaction of TerB with the negatively charged phosphate groups of the phospholipid membrane (Fig. 1C).

Cross-linking reagent provides the protein-protein complexes to be assembled by covalently bonding them together. Because the function of some revealed interacting partners is connected mainly to ATP synthesis, we propose that TerB protein may be involved in $\mathrm{TeO}_{3}{ }^{2-}$ reduction in the cell. Several oxidoreductases, including nitrate reductase and terminal oxidases of the bacterial respiratory chain (Avazeri et al. 1997; Trutko et al. 1998) can contribute to tellurite reduction. The nitrate reductase activities present in membrane fractions of the model eubacterium $E$. coli can mediate the reduction of tellurite. Subunit G of the NADH-quinone oxidoreductase, a proton-translocating enzyme complex of the respiratory chain, is one of the proteins co-localized with TerB. Subunit $\mathrm{G}$ is a component of the soluble NADH dehydrogenase part, which also harbors the flavin mononucleotide and four EPR-detectable FeS clusters. It has been suggested that a flavine-dependent reductase located at the

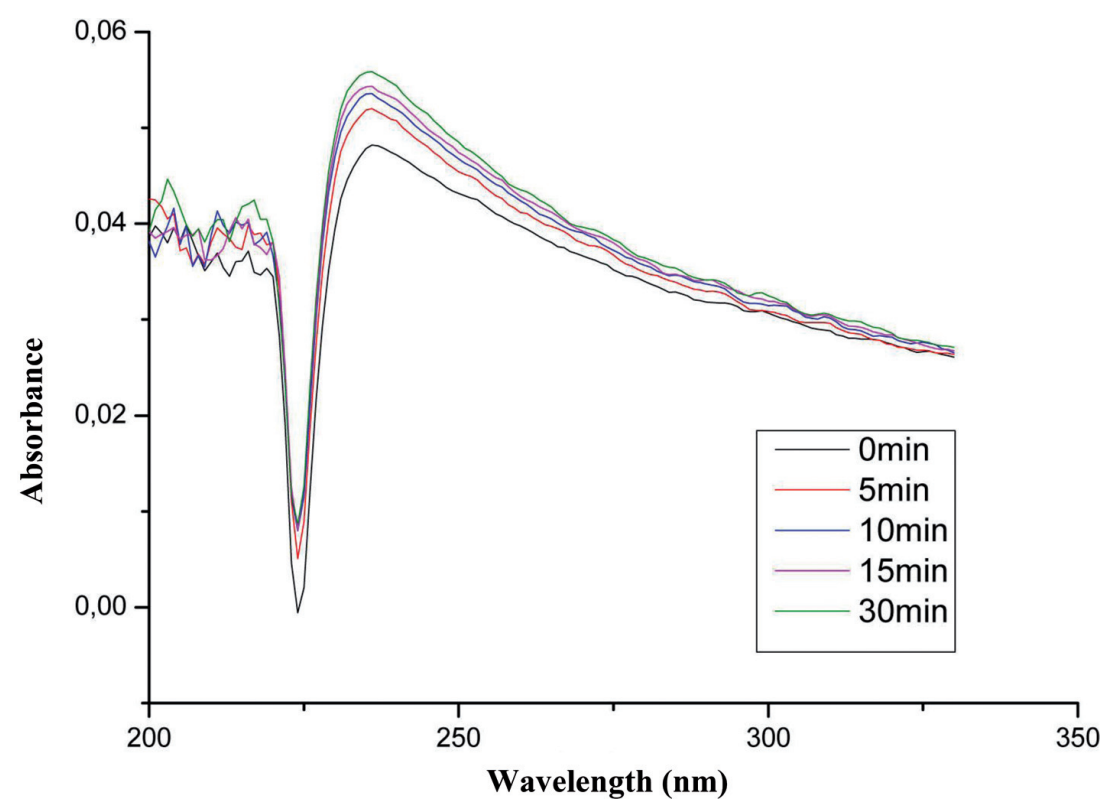

Figure 3. Ultraviolet (UV) difference spectrum of TerB with negative charged liposomes at different time points. 
Table 1. Proteins co-localized with TerB after cross-linking treatment

\begin{tabular}{|c|c|c|c|c|c|}
\hline Protein & Accession No. & Mass (Da) & MASCOT score & Function & Localization \\
\hline Bifunctional polymyxin resistance protein arnA & C4ZU97 & 74242 & 95 & Antibiotic resistance & cytosolic \\
\hline $\begin{array}{l}\text { Glucosamine-fructose-6-phosphate } \\
\text { aminotransferase }\end{array}$ & Q8XEG2 & 66867 & 212 & $\begin{array}{l}\text { Glutamine metabolic } \\
\text { process }\end{array}$ & cytosolic \\
\hline ATP synthase subunit alpha & A7ZTU6 & 55188 & 155 & ATP synthesis & cytosolic \\
\hline Catabolite gene activator & P0ACK0 & 23625 & 103 & Transcription regulation & cytosolic \\
\hline Protein translocase subunit secA & A7ZHI9 & 101959 & 161 & Protein transport & membrane \\
\hline NADH-quinone oxidoreductase subunit $G$ & Q8XCX2 & 100240 & 62 & $\begin{array}{l}\text { ATP synthesis coupled } \\
\text { electron transport }\end{array}$ & membrane \\
\hline Chaperon protein dnaK & P0A6Z0 & 69072 & 172 & Protein folding & membrane \\
\hline Elongation factor Tu1 & A7ZSL4 & 43256 & 126 & Protein biosynthesis & membrane \\
\hline
\end{tabular}

Accession numbers and functional information of proteins were taken from UniProt.

plasma membrane could play an essential role in $\mathrm{TeO}_{3}{ }^{2-}$ reduction (Moore and Kaplan 1992). In this study, co-localized ATP synthase subunit alpha was identified. This cross-linked partner of TerB is involved in the membrane ATP synthesiscoupled proton transport. Protein translocase subunit secA was also found which plays a central role in coupling of ATP hydrolysis to the transfer of proteins into and across the cell. Two remarked proteins, DnaK and elongation factor Tu1 can be understood as the background proteins (Shevchenko et al. 2002; Kocks et al. 2003).

Taken together, the obtained results support the hypothesis that essential tellurite resistance protein TerB is involved in the process of tellurite reduction. The protein-protein interaction
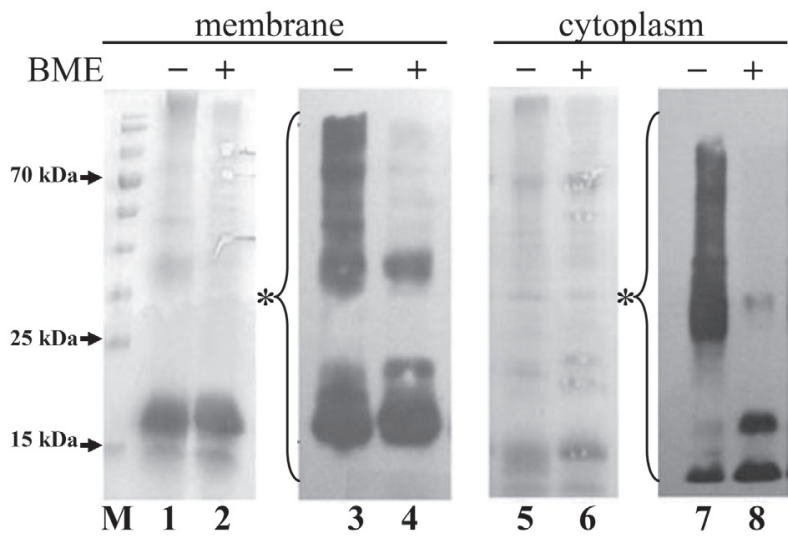

Figure 4. Analysis of polypeptides in vivo cross-linked to TerB by DSP agent. SDS-PAGE (lanes 1, 2, 5, 6) and Western blot analysis (lanes $3,4,7,8$ ) of the cytoplasmic and membrane fractions prepared from DSP-treated cells (E. coli BL21(DE3) with pETterB expression plasmid). Aliquots of each fraction were analyzed by $12 \%$ SDS PAGE in the presence $(+)$ or absence $(-)$ of $\beta$-mercaptoethanol (BME). * products of cross-linking; M, PageRuler ${ }^{\text {rax }}$ Prestained Protein Ladder (Fermentas). candidates revealed within in vivo cross-link assay can contribute to the further experiments able to disclose the possible mechanisms of the tellurite resistance of bacterial cell.

Acknowledgements. This work was supported by APVV 20-054005 project and a grant from VEGA 1/0346/10.

\section{References}

Avazeri C., Turner R. J., Pommier J., Weiner J. H., Giordano G., Vermeglio A. (1997): Tellurite reductase activity of nitrate reductase is responsible for the basal resistance of Escherichia coli to tellurite. Microbiology 143, 1181-1189 doi:10.1099/00221287-143-4-1181

Borsetti F., Tremaroli V., Michelacci F., Borghese R., Winterstein C., Daldal F., Zannoni D. (2005): Tellurite effects on Rhodobacter capsulatus cell viability and superoxide dismutase activity under oxidative stress conditions. Res. Microbiol. 7, 807-813 doi:10.1016/j.resmic.2005.03.011

Burian J., Nguyen T., Klucar L., Guller L., Lloyd-Jones G., Stuchlik S., Frejdi P., Siekel P., Turna J. (1998): In vivo and in vitro cloning and phenotype characterization of tellurite resistance determinant conferred by plasmid pTE53 of clinical isolate of Escherichia coli. Folia Microbiol. 43, 589-599 doi:10.1007/BF02816374

Burian J., Macor M., Langsandl L., Beno J., Guller L., Siekel P. (1988): Prevalence of plasmids and analysis of resistances in clinical strains of Escherichia coli. Cs. Epidem. 37, 329-335

Calderon I. L., Arenas F. A., Perez, J. M., Fuentes D. E., Araya M. A., Saavedra C. P., Tantalean J. C., Pichuantes S. E., Youderian P. A., Vasquez C. C. (2006): Catalases are NAD(P)H-dependent tellurite reductases. PloS One 1, 70 doi:10.1371/journal.pone. 0000070

Chasteen T. G., Fuentes D. E., Tantalean J. C., Vasquez C. C. (2009): Tellurite: history, oxidative stress and molecular mechanism of resistance. FEMS Microbiol. Rev. 33, 820-832 doi:10.1111/j.1574-6976.2009.00177.x

Chen Y. T., Chang H. Y., Lai Y. C., Pan C. C., Tsai S. F., Peng H. L. (2004): Sequence and analysis of the large virulence 
plasmid pLVPK of Klebsiella pneumoniae CG43. Gene 337, 189-198 doi:10.1016/j.gene.2004.05.008

Chiang S. K., Lou Y. C., Chen C. (2008): NMR solution structure of KP-TerB, a tellurite-resistance protein from Klebsiella pneumoniae. Protein Sci. 17, 785-789 doi:10.1110/ps.073389408

Cornell R. B., Taneva S. G. (2006): Amphipathic helices as mediators of the membrane interaction of amphitropic proteins, and as modulators of bilayer physical properties. Curr. Protein Pept. Sci. 7, 539-552 doi:10.2174/138920306779025675

Creighton T. E. (1997): Protein structure. A practical approach. Pp. 261-297, Oxford University Press U.S.A.

Dym O., Pratt E. A., Ho C., Eisenberg D. (2000): The crystal structure of D-lactate dehydrogenase, a peripheral membrane respiratory enzyme. Proc. Natl. Acad. Sci. U.S.A. 97, 9413-9418 doi:10.1073/pnas.97.17.9413

Huber L. A., Pfaller K., Vietor I. (2003): Organelle proteomics: implications for subcellular fractionation in proteomics. Circ. Res. 92, 962-968 doi:10.1161/01.RES.0000071748.48338.25

Jobling M. G., Ritchie D. A. (1988): The nucleotide sequence of a plasmid determinant for resistance to tellurium anions. Gene 66, 245-258 doi:10.1016/0378-1119(88)90361-7

Johnson J. E., Cornell R. B. (1999): Amphitropic proteins: Regulation by reversible membrane interactions. Mol. Membr. Biol. 16, 217-235 doi:10.1080/096876899294544

Kentsis A., Gordon R. E., Borden K. L. B. (2002): Control of biochemical reactions through supramolecular RING domain selfassembly. Proc. Natl. Acad. Sci. U.S.A. 99, 15404-15409 doi:10.1073/pnas.202608799

Kocks C., Maehr R., Overkleeft H. S., Wang E. W., Iyer L. K., Lennon-Dumenil A. M., Ploegh H. L., Kessler B. M. (2003): Functional proteomics of the active cysteine protease content in Drosophila S2 cells. Mol. Cell Proteomics 2, 1188-1197 doi:10.1074/mcp.M300067-MCP200

Kormutakova R., Klucar L., Turna J. (2000): DNA sequence analysis of the tellurite-resistance determinant from clinical strain of Escherichia coli and identification of essential genes. Biometals 13, 135-139 doi:10.1023/A:1009272122989

Lopez-Villar E., Monteoliva L., Larsen M. R., Sachon E., Shabaz M., Pardo M., Pla J., Gil C., Roepstorff P., Nombela C. (2006): Genetic and proteomic evidences support the localization of yeast enolase in the cell surface. Proteomics 6 (Suppl. 1), S107-118 doi:10.1002/pmic.200500479

Moore M., Kaplan S. (1992): Identification of intrinsic high-level resistance to rare-earth oxides and oxyanions in members of the class Proteobacteria: characterization of tellurite, selenite, and rhodium sesquioxide reduction in Rhodobacter sphaeroides. J. Bacteriol. 174, 1505-1514

Perez J. M., Calderon I. L., Arenas F. A., Fuentes D. E., Pradenas G. A., Fuentes E. L., Sandoval J. M., Castro M. E., Elias A. O., Vasquez C. C. (2007): Bacterial toxicity of potassium tellurite: unveiling an ancient enigma. PLoS One 2, e211 doi:10.1371/journal.pone.0000211

Perna N. T., Mayhew G. F., Posfai G., Elliott S., Donnenberg M. S., Kaper J. B., Blattner F. R. (1998): Molecular evolution of pathogenicity island from enterohemorrhagic Escherichia coli O157:H7. Infect. Immun. 66, 3810-3817

Shevchenko A., Schafts D., Roguev A., Pijnappel W. W., Stewart A. F., Shevchenko A. (2002): Deciphering protein complexes and protein interaction networks by tandem affinity purification and mass spectrometry: analytical perspective. Mol. Cell Proteomics 1, 204-212 doi:10.1074/mcp.M200005-MCP200

Tantalean J. C., Araya M. A., Saavedra C. P., Fuentes D. E., Perez J. M., Calderon I. L., Youderian P., Vasquez C. C. (2003): The Geobacillus stearothermophilus $\mathrm{V}$ iscS gene, encoding cysteine desulfurase, confers resistance to potassium tellurite in Escherichia coli K-12. J. Bacteriol. 185, 5831-5837 doi:10.1128/JB.185.19.5831-5837.2003

Taylor D. E. (1999): Bacterial tellurite resistance. Trends Microbiol. 7, 111-115 doi:10.1016/S0966-842X(99)01454-7

Toptchieva A., Sisson G., Bryden L. J., Taylor D. E., Hoffman P. S. (2003): An inducible tellurite-resistance operon in Proteus mirabilis. Microbiology 149, 1285-1295 doi:10.1099/mic.0.25981-0

Tremaroli V., Fedi F., Zannoni D. (2006): Evidence for a telluritedependent generation of reactive oxygen species and absence of a tellurite-mediated adaptive response to oxidative stress in cells of Pseudomonas pseudoalcaligenes KF707. Arch. Microbiol. 187, 127-135 doi:10.1007/s00203-006-0179-4

Trutko S. M., Suzina N. E., Duda V. I., Akimenko V. K., Boronin A. M. (1998): Participation of the bacterial respiratory chain in reduction of potassium tellurite. Dokl. Akad. Nauk. 358, 836-838 (in Russian)

Turner R. J., Hou Y., Weiner J. H., Taylor D. E. (1992): The arsenical ATPase efflux pump mediates tellurite resistance. J. Bacteriol. 174, 3092-3094

Turner R. J., Weiner J. H., Taylor D. E. (1994): Characterization of the growth inhibition phenotype of the kilAtelB operon from IncPa plasmid RK2TeR. Biochem. Cell Biol. 72, 333-342 doi:10.1139/o94-046

Vavrova S., Valkova D., Drahovska H., Kokavec J., Mravec J., Turna J. (2006): Analysis of the tellurite resistance determinant on the pNT3B derivative of the pTE53 plasmid from uropathogenic Escherichia coli. Biometals 19, 453-460 doi: 10.1007/s10534-005-4862-8

Whelan K. F., Sherburge R. K., Taylor D. E. (1997): Characterization of a region of the IncHI2 plasmid R478 which protects Escherichia coli from toxic effects specified by components of tellurite, phage and colicin resistance cluster. J. Bacteriol. $178,63-71$

Zannoni D., Borsetti F., Harrison J. J., Turner R. J. (2008): The bacterial response to the chalcogen metalloids Se and Te. Adv. Microb. Physiol. 53, 1-72 doi:10.1016/S0065-2911(07)53001-8

Received: August 23, 2010

Final version accepted: May 10, 2011 